\title{
Study of the Mean Platelet Volume in Children with Chronic Renal Diseases
}

Ali Mohamed Abu-Zeid ${ }^{1}$, Saed Mohamed Morsy ${ }^{2}$, Sherif Hassan Mohamed ${ }^{1}$

Departments of ${ }^{1}$ Pediatrics and ${ }^{2}$ Biochemistry, Faculty of Medicine, Zagazig University, Sharkia, Egypt

*Corresponding author: Sherif Hassan Mohamed Fawzy, Mobile: (+20)01002327771,

E-Mail:sherif.hassan021@gmail.com

\begin{abstract}
Background: The mean platelet volume (MPV), which is a readily available indicator of platelet activation and function, is considered as a promising predictive and prognostic biomarker of cerebrovascular and cardiovascular diseases in several studies. The larger platelets tend to aggregate and produce larger amounts of adhesion molecules than small ones.

Objective: To investigate the relationship between MPV levels and the glomerular filtration rate (GFR) in pediatric patients with Chronic Kidney Disease (CKD).

Patients and Methods: A prospective case-control study was carried out at the Nephrology Unit in the pediatric department of Zagazig University Children Hospitals.40 children participated in study 20 of them having chronic kidney disease as a case group and a similar number of control children comparable with case group. We reviewed the medical records of patients between May 2018 and February 2019.

Results: In this study, there was a positive significant correlation between MPV with Red cell Distribution Width (RDW) and creatinine and a negative correlation between MPV and eGFR in the CKD group. There was a statistically significant difference between case and control groups as regard serum creatinine, urea, and eGFR. There was a highly significant difference between the two groups regarding Hemoglobin, MPV, and RDW. There was a statistically significant difference between the two groups regarding systolic blood pressure (SBP) and diastolic blood pressure (DBP). There was a significant difference between the two studied groups as regard weight. MPV was significantly increased with the progression of CKD. Thus the lower the results of eGFR reflecting poor stage and prognosis of chronic kidney disease accompanied by higher values of MPV.

Conclusion: The useful estimation of MPV provides a promising Cheap Biomarker in the monitoring of the course of progression in Chronic Kidney Diseased Children.
\end{abstract}

Keywords: CKD, MPV, eGFR, SBP, DBP, RDW.

\section{INTRODUCTION}

Chronic kidney disease (CKD) is a major worldwide health problem with increasing incidence and prevalence. The prevalence of all stages of CKD varies between $7-12 \%$ in the different regions of the world. Chronic Kidney Disease in low and middle-income countries is poorly characterized owing to the lack of community-based studies ${ }^{(\mathbf{1})}$. Little is known about CKD in children because children are not included in many clinical studies. It has a significant effect on the health status of a wide range population and affects the economic state of society considering the high cost of renal replacement and management ${ }^{(2)}$.

The definition of chronic kidney disease is a decrease in kidney function estimated by Glomerular Filtration Rate (GFR) of less than $60 \mathrm{ml} / \mathrm{min} / 1.73 \mathrm{~m}^{2}$, or by markers of kidney structure damage, or both of them for at least 3 months duration, whatever was the underlying cause. The best indicator of kidney function is GFR, which is measured either by exogenous markers or estimated using Creatinine-Based "Beside Schwartz" Equation in children ${ }^{(3)}$.

Mean platelet volume (MPV) is the average volume of a single platelet measured in femtolitres (fL) and is considered an inexpensive marker that routinely is measured in labs by automated cell counters. More large platelets are being activated than the smaller platelets ${ }^{(4)}$.

High MPV is associated with a variety of many diseases in children and adults as Familial Mediterranean Fever \&Myocardial Infarction, Also it is considered as a useful biomarker in patients with cardiovascular diseases using Percutaneous Coronary Intervention (PCI) and in the prognosis of many patients of acute cerebrovascular disorders ${ }^{(5)}$.

Recent few studies of using MPV as a biomarker in patients with renal disease have been done revealed high values of MPV in CKD patients. This study aimed to determine the relationship between Mean Platelet Volume \& estimated Glomerular Filtration Rate in Children with Chronic Kidney Disease ${ }^{(6)}$.

\section{AIM OF THE WORK}

To determine the relationship between Mean Platelet Volume \& estimated Glomerular Filtration Rate in Children with Chronic Kidney Disease.

\section{PATIENTS AND METHODS}

This study was a case-control study and had been performed in the period from May 2018 to February 2019 in the Nephrology Unit, Pediatric Department of Zagazig University Hospitals. Total subjects included 40 patients in 
2 groups, control group: 20 patients from the outpatient clinic who don't have hemostatic disorders and a case group:20 patients (male and female) aged from 1-14 years with Chronic Kidney Disease lasting $\geq 3$ months and who having frequent dialysis or conservative treatment and their estimated GFR equal or less than $60 \mathrm{ml} / \mathrm{min} / 1.73 \mathrm{~m}^{2}$. We excluded patients having a history of receiving treatment affecting hemostasis or platelets as malignancy, hematologic disorders (as ITP), and chronic liver disease patients.

\section{Ethical Consideration:}

Written informed consent was obtained from all subject parents and the study was carried according to the research ethics committee of the Faculty of Medicine, Zagazig University. This study was carried according to the Code of Ethics of the World Medical Association (Declaration of Helsinki) for studies involving humans.

Clinical evaluation and laboratory data all patients have been subjected to: Detailed history taking including (personal history, present history, past history of previous renal effect, vaccination history, dietetic history, and family history of similar illness).

Clinical Examination is done as follows: General examination: level of consciousness, complexion (pallor, jaundice, edema), Vital signs: Temperature-Respiratory rate - Heart rate and blood pressure, Anthropometric measurements (weight, height, head circumference, and mid-arm circumference), Systemic examination with special emphasis on renal and abdominal examination (distention, tenderness, organomegaly), Local Abdomen \& Pelvis examination by Inspection for (movements, localized bulge or localized retraction and signs of edema), palpation, percussion and auscultation

Complete blood picture (CBC), Liver function tests: serum bilirubin (total and direct), serum albumin, serum alanine transaminase, and aspartate have been investigated. Kidney function tests: serum creatinine, serum urea using automated analyzer Estimation of eGFR by Schwartz equation: $\mathrm{eGFR}=\mathrm{k}$ (Constant) $\mathrm{x}$ height in $\mathrm{cm} / \mathrm{serum}$ creatinine.

Kidney \& Urinary Bladder X-ray done showing (opacity, fibrosis, exaggerated markings, etc.).Abdominal and Pelvic ultrasound to exclude other liver and kidney disease according to examination. CT (if needed).

\section{Statistical Analysis}

Data were collected and statistically analyzed using the SPSS program (Statistical Package for Social Science) version 20. Chi-square test $(\chi 2)$ and Fisher exact were used to calculate the difference between qualitative variables as indicated. All statistical comparisons were two-tailed with significance Level. P-value $\leq 0.05$ indicates significant, $\mathrm{p}$ $<0.001$ indicates highly significant difference while, $\mathrm{P}\rangle$ 0.05 indicates Non-significant difference.

\section{RESULTS}

Table (1), showed that there was a significant difference between the two studied groups as regard weight. Table (2), showed that there was a significant difference between the two groups regarding SBP and DBP. Table (3), showed that there was a significance difference between the two groups regarding Hemoglobin, MPV, and RDW. Table (4), showed that there was a significant difference between the two groups regarding serum creatinine, urea, and eGFR. Table (5), showed that there was a significant difference between the two groups regarding serum albumin. Table (6), showed that there was a positive significant correlation between MPV with RDW and creatinine and a negative correlation between MPV and eGFR in the CKD group.

Table (1): Demographic data distribution of the two studied groups

\begin{tabular}{|c|c|c|c|c|c|}
\hline \multicolumn{2}{|c|}{ Variable } & $\begin{array}{c}\text { Controls } \\
(n=20)\end{array}$ & $\begin{array}{c}C K D \\
(n=20)\end{array}$ & $t / \chi^{2}$ & P-Value \\
\hline \multicolumn{2}{|c|}{$\begin{array}{l}\text { Age (years) } \\
\text { Mean } \pm S D\end{array}$} & $9.25 \pm 2.07$ & $9.75 \pm 2.25$ & .732 & .469 \\
\hline \multicolumn{2}{|c|}{$\begin{array}{c}\text { BMI }\left(\mathrm{kg} / \mathrm{m}^{2}\right) \\
\text { Mean } \pm S D\end{array}$} & $19.78 \pm 2.92$ & $21.52 \pm 3.74$ & 1.634 & .111 \\
\hline \multicolumn{2}{|c|}{$\begin{array}{l}\text { Height }(\mathrm{cm}) \\
\text { Mean } \pm S D\end{array}$} & $147.75 \pm 10.68$ & $149.1 \pm 13.37$ & .353 & .726 \\
\hline \multicolumn{2}{|c|}{$\begin{array}{l}\text { Weight }(\mathrm{kg}) \\
\text { Mean } \pm S D\end{array}$} & $43.3 \pm 9.19$ & $50.85 \pm 10.46$ & 2.425 & .020 \\
\hline \multirow{2}{*}{ Sex } & Male & $14(70 \%)$ & $13(65 \%)$ & \multirow{2}{*}{.114} & \multirow{2}{*}{.736} \\
\hline & Female & $6(30 \%)$ & $7(35 \%)$ & & \\
\hline
\end{tabular}

Table (2): Blood Pressure data of the two studied groups

\begin{tabular}{|c|c|c|c|c|}
\hline Variable & $\begin{array}{c}\text { Controls } \\
(\boldsymbol{n}=20)\end{array}$ & $\begin{array}{c}\boldsymbol{C K D} \\
(\boldsymbol{n}=20)\end{array}$ & $\boldsymbol{t} / \chi 2$ & $\boldsymbol{P}$-Value \\
\hline SBP $($ Mean $\pm S D)$ & $124.25 \pm 7.24$ & $137 \pm 16.74$ & $\mathbf{2 . 2 6 1}$ & $\mathbf{. 0 1 3}$ \\
\hline $\begin{array}{c}\text { DBP } \\
\text { Mean } \pm S D\end{array}$ & $82.00 \pm 6.52$ & $93.25 \pm 14.50$ & $\mathbf{3 . 4 4 9}$ & $\mathbf{. 0 0 9}$ \\
\hline
\end{tabular}


Systolic Blood Pressure (SBP), Diastolic Blood Pressure (DBP)

Table (3): CBC parameters of the two studied groups

\begin{tabular}{|c|c|c|c|c|}
\hline Variable & $\begin{array}{c}\text { Controls } \\
(n=20)\end{array}$ & $\begin{array}{c}\text { CKD } \\
(n=20)\end{array}$ & $\boldsymbol{t}$ & P-Value \\
\hline $\begin{array}{c}\text { HB }(g / d L) \\
\text { Mean } \pm S D\end{array}$ & $11.75 \pm 1.28$ & $10.58 \pm .639$ & $\mathbf{3 . 6 5 5}$ & $\mathbf{. 0 0 1}$ \\
\hline $\begin{array}{c}\text { MCV }(f L) \\
\text { Mean } \pm S D\end{array}$ & $76.55 \pm 5.58$ & $75.8 \pm 7.64$ & 3.55 & .725 \\
\hline $\begin{array}{c}\text { MCH }(p g) \\
\text { Mean } \pm S D\end{array}$ & $30.85 \pm 2.41$ & $31.65 \pm 1.89$ & 1.165 & .251 \\
\hline $\begin{array}{c}\text { MCHC }(g / d L) \\
\text { Mean } \pm S D\end{array}$ & $25.85 \pm 3.54$ & $27.9 \pm 3.24$ & 1.909 & .064 \\
\hline $\begin{array}{c}\text { TLC }\left(10^{9} / L\right) \\
\text { Mean } \pm S D\end{array}$ & $7.27 \pm 2.21$ & $9.09 \pm 2.4$ & 1.336 & .189 \\
\hline $\begin{array}{c}\text { PLT }\left(10^{9} / L\right) \\
\text { Mean } \pm S D\end{array}$ & $306.1 \pm 15.55$ & $311.6 \pm 8.12$ & .186 & .854 \\
\hline $\begin{array}{c}\text { MPV }(f L) \\
\text { Mean } \pm S D\end{array}$ & $7.77 \pm 0.225$ & $10.77 \pm 1.28$ & $\mathbf{1 0 . 3 7 7}$ & $\mathbf{. 0 0 1}$ \\
\hline $\begin{array}{c}\text { RDW }(\%) \\
\text { Mean } \pm S D\end{array}$ & $13.44 \pm 0.424$ & $17.02 \pm 1.08$ & $\mathbf{1 3 . 7 7 4}$ & $\mathbf{. 0 0 1}$ \\
\hline
\end{tabular}

Hemoglobin Level (HB), Mean Corpuscular Volume (MCV), Mean Corpuscular Hemoglobin (MCH), Mean Corpuscular Hemoglobin Concentration (MCHC), Total Leucocytes Count (TLC), Platelet (PLT), Mean Corpuscular Volume (MPV), Red cell Distribution Width (RDW)

Table (4): Renal parameters of the two studied groups

\begin{tabular}{|c|c|c|c|c|}
\hline Variable & $\begin{array}{c}\text { Controls } \\
(n=20)\end{array}$ & $\begin{array}{c}C K D \\
(n=20)\end{array}$ & $T$ & P-Value \\
\hline $\begin{array}{c}\text { Creatinine }(\mathrm{mg} / \mathrm{dL}) \\
\text { Mean } \pm S D\end{array}$ & $.685 \pm .118$ & $2.5 \pm .539$ & 14.710 & .001 \\
\hline $\begin{array}{c}\text { Urea }(m g / d L) \\
\text { Mean } \pm S D\end{array}$ & $12.34 \pm 1.36$ & $64.74 \pm 4.34$ & 11.166 & .001 \\
\hline $\begin{array}{c}\text { eGFR }\left(\mathrm{ml} / \mathrm{min} / 1.73 \mathrm{~m}^{2}\right) \\
\text { Mean } \pm S D\end{array}$ & $91.54 \pm 16.21$ & $26.04 \pm 6.15$ & 16.897 & .001 \\
\hline
\end{tabular}

\section{Estimated Glomerular Filtration Rate (eGFR)}

Table (5): Liver parameters of the two studied groups

\begin{tabular}{|c|c|c|c|c|}
\hline Variable & $\begin{array}{c}\text { Controls } \\
(n=20)\end{array}$ & $\begin{array}{c}\text { CKD } \\
(n=20)\end{array}$ & $\boldsymbol{T}$ & P-Value \\
\hline $\begin{array}{c}\text { Total Bil. }(\mathrm{mg} / \mathrm{dL}) \\
\text { Mean } \pm S D\end{array}$ & $.475 \pm .038$ & $.567 \pm .08$ & .419 & .680 \\
\hline $\begin{array}{c}\text { Direct Bil. }(\mathrm{mg} / \mathrm{dL}) \\
\text { Mean } \pm S D\end{array}$ & $.239 \pm .027$ & $.338 \pm .029$ & .812 & .426 \\
\hline $\begin{array}{c}\text { ALT }(\mathrm{U} / \mathrm{L}) \\
\text { Mean } \pm S D\end{array}$ & $30.05 \pm 3.47$ & $28.2 \pm 2.42$ & .212 & .834 \\
\hline $\begin{array}{c}\text { AST }(\mathrm{U} / \mathrm{L}) \\
\text { Mean } \pm S D\end{array}$ & $33.01 \pm 4.62$ & $29.5 \pm 7.38$ & .436 & .666 \\
\hline $\begin{array}{c}\text { Total protein }(\mathrm{g} / \mathrm{dL}) \\
\text { Mean } \pm S D\end{array}$ & $5.43 \pm 1.15$ & $5.48 \pm 1.23$ & .089 & .930 \\
\hline $\begin{array}{c}\text { Albumin }(g / d L) \\
\text { Mean } \pm S D\end{array}$ & $4.13 \pm .684$ & $3.37 \pm .716$ & $\mathbf{2 . 2 5 9}$ & $\mathbf{. 0 3 5}$ \\
\hline
\end{tabular}

Bilirubin (Bil), Alanine Aminotransferase (ALT), Aspartate Aminotransferase (AST) 
Table (6): Correlation of MPV with other parameters in two groups

\begin{tabular}{|c|c|c|c|}
\hline \multicolumn{2}{|c|}{ Variable } & Controls & $C K D$ \\
\hline \multirow{2}{*}{ Age } & $r$ & -.141 & .260 \\
\hline & $p$ & .553 & .267 \\
\hline \multirow{2}{*}{ Weight } & $r$ & .035 & -.102 \\
\hline & $p$ & .883 & .669 \\
\hline \multirow{2}{*}{ Height } & $r$ & -.008 & .027 \\
\hline & $p$ & .974 & .909 \\
\hline \multirow{2}{*}{ BMI } & $r$ & -.014 & -.062 \\
\hline & $p$ & .954 & .794 \\
\hline \multirow{2}{*}{ Hemoglobin } & $r$ & -.334 & .016 \\
\hline & $p$ & .150 & .946 \\
\hline \multirow{2}{*}{$T L C$} & $r$ & -.152 & -.121 \\
\hline & $p$ & .521 & .612 \\
\hline \multirow{2}{*}{$P L T$} & $r$ & .128 & -.196 \\
\hline & $p$ & .592 & .406 \\
\hline \multirow{2}{*}{$M C V$} & $r$ & -.242 & -.027 \\
\hline & $p$ & .304 & .910 \\
\hline \multirow{2}{*}{ MCH } & $r$ & -.212 & -.207 \\
\hline & $p$ & .369 & .381 \\
\hline \multirow{2}{*}{ МСHC } & $r$ & -.212 & -.089 \\
\hline & $p$ & .640 & .710 \\
\hline \multirow{2}{*}{$R D W$} & $r$ & .228 & $.914 * *$ \\
\hline & $p$ & .333 & .000 \\
\hline \multirow{2}{*}{ Creatinine } & $r$ & .299 & $.960 * *$ \\
\hline & $p$ & .201 & .000 \\
\hline \multirow{2}{*}{$e G F R$} & $r$ & -.365 & $-.876 * *$ \\
\hline & $p$ & .113 & .000 \\
\hline
\end{tabular}

\section{DISCUSSION}

This study showed that the mean value of MPV in femtolitre (fL) was statistically significant higher among CKD patients $(10.77 \pm 1.28 \mathrm{fL})$ than controls $(7.77 \pm .225$ $\mathrm{fL})$ with $(\mathrm{P}$ value $=0.00)$, these results were in agreement with the study of Koroglu et al. ${ }^{(7)}$ who observed a high MPV in CKD patients and concluded that MPV can be used as a biomarker to estimate atherosclerosis risk in CKD patients and patients on hemodialysis., while Lokesh et al. ${ }^{(8)}$ who aimed to study the platelet distribution width (PDW), mean platelet volume, platelet count, among ESRD patients undergoing hemodialysis (HD) and compare with healthy age and sex-matched controls. Group A (Cases) consisting of 40 ESRD patients receiving $\mathrm{HD}$ for more than 6 months, and group $\mathrm{B}$ (controls) consisting of 40 healthy controls matched for age and sex. MPV among cases was $(11.37 \pm 1.26 \mathrm{fL})$ as compared to $(11.43 \pm 1.22 \mathrm{fL})$ in the control group, which was not found to be statistically significant $(\mathrm{p}=0.809)$.

In the present study, there was a negative correlation between MPV and eGFR in the CKD group. This coincides with Yilmaz et al. ${ }^{(9)}$ who found that, a negative correlation between MPV and eGFR in the CKD group.
This also agrees with Ju et al. ${ }^{(10)}$ and Tamadon et al. ${ }^{(11)}$ who reported that there was a negative linear correlation between GFR and MPV in patients with chronic kidney failure.

This study showed that the mean value of weight $(\mathrm{kg})$ was statistically significant higher among CKD than controls and this disagrees with the study of El Sadek $\boldsymbol{e t}$ al. (12) who aimed to evaluate psychological problems including aggression and anxiety disorders in children with CKD on regular hemodialysis compared to healthy children where no statistically significant difference found between patients and control.

In the present study, mean values of SBP and DBP of the patient's group were significantly higher than that of the control group and this agrees with studies of Samuels et al. ${ }^{(13)}$ and El-Gamasy et al. ${ }^{(14)}$ who aimed to analyze to describe the association between renal function decline and the presence of abnormal Blood Pressure in the United States.

In our study, causes of CKD in cases group the most common was FSGS (22.7\%), Bilateralatrophickidneys (13.6\%), Neurogenicbladder (13.6\%), Reflux (4.5\%), ARPKD (4.5\%), Chronic interstitial nephritis (4.5\%), 
GN(4.5\%), Polycystic kidney(4.5\%), This is consistent with Vivante and Hildebrandt ${ }^{(15)}$ who reported that primary causes of CKD in children significantly differ from those that are responsible for the adult onset of the disease.

In the current study, the mean value of $\mathrm{HB}$ was statistically significant lower among CKD cases than controls. Fishbane and Spinowitz ${ }^{(16)}$ attributed this among patients with CKD, there is a relative deficiency in erythropoietin production, and this is the main reason that anemia develops.

In the present study, the mean value of RDW (\%) was statistically significant Higher among CKD than Controls. This is consistent with $\mathbf{L i}$ et al. ${ }^{(17)}$ and also agrees with Bazeed et al. ${ }^{(18)}$ who found that; the mean value of RDW (\%) was statistically significant Higher among CKD than Controls.

In the current study, there was no statistically significant difference between patients and control regarding (AST) aspartate aminotransferase, (ALT) alanine aminotransferase, Direct Serum Bilirubin, and Total Serum Bilirubin. This is consistent with Hartung et al. (19) who found that, no statistically significant difference between patients and control regarding liver functions.

\section{LIMITATIONS OF THE STUDY}

In our study, there are some limitations as a short period of the study as it would be better to be done on a larger scale of time for magnifying the results according to the prognosis of CKD patients. Also, the number of case group as 20 patients may give limited data as compared if done with the participation of a larger number of patients and control groups. Another limitation is that there are little researches using MPV as a parameter in kidney disease patient with little limitation of the scope of discussion.

\section{RECOMMENDATIONS}

- Great care is necessary during the treatment of CKD Children patients with higher MPV.

- Large studies with long term follow up is needed to study the rule of MPV with other markers in monitoring CKD in Children patients.

- Conflict of interest: No

- Financial disclosure: No

\section{REFERENCES}

1. Delanaye P, Glassock R, De Broe M (2017): Epidemiology of chronic kidney disease: think (at least) twice! Clin Kidney J., 10(3): 370-374

2. Miller W, Jones G (2018): Estimated Glomerular Filtration Rate; Laboratory implementation and Current Global Status. Adv Chronic Kidney Dis., 25(1):7-13.

3. Dai Z, Gao J, Li S et al. (2018): Mean Platelet Volume as a predictor for restenosis after carotid angioplasty and stenting. Stroke, 49(4):872-876.
4. Tian C, Song J, He D et al. (2018): Predictive value of Mean Platelet Volume/Platelet count for prognosis in Acute Myocardial Infarction. Int Heart J., 59(2):286-292.

5. Turgutalp K, Özhan O, Akbay E et al. (2014): Mean platelet volume and related factors in patients at different stages of diabetic nephropathy: a preliminary study. Clin Appl Thromb Hemost., 20(2):190-5.

6. Yilmaz G, Sevinc C, Ustundag S et al. (2017): The relationship between mean platelet volume and neutrophil/lymphocyte ratio with inflammation and proteinuria in chronic kidney disease. Saudi J Kidney Dis Transpl., 28(1):90-94.

7. Koroglu M, Akalin N, Ozkan H et al. (2015): Importance of platelet markers for demonstrating the presence of inflammation in different stages of chronic renal diseases. Eur J Basic Med Sci., 5(1): 1-9.

8. Lokesh S, Siva R, Kadavanu T et al. (2016): A comparative study of platelet parameters in end-stage renal disease patients undergoing hemodialysis and healthy individuals. Int $\mathbf{J}$ Adv Med., 3:559-63.

9. Yilmaz G, Sevinc C, Ustundag S et al. (2018): The relationship between mean platelet volume and neutrophil/lymphocyte ratio with inflammation and proteinuria in chronic kidney disease. Saudi J Kidney Dis Transpl., 28:90-4.

10.Ju H, Kim J, Hur S et al. (2015): could mean platelet volume be a promising biomarker of progression of chronic kidney disease? Platelets, 26:143-7.

11.Tamadon M, Torabi S, Moghimi J et al. (2018): Serum creatinine levels in relationship with mean platelet volume in patients with chronic kidney disease. J Renal Inj Prev., 7(1):38-41.

12.El Sadek S, El Shafee T, Zaher M (2013): Anxiety and Aggression Disorders of Children with Chronic Kidney Disease on Regular Hemodialysis. Life Sci J., 10(3):598-603.

13.Samuels J, Ng D, Flynn J et al. (2013): Ambulatory Blood Pressure Patterns in Children with Chronic Kidney Disease. PMC., 60(1): 43-50.

14. El-Gamasy M, Aboelhana N, Abdelhafez M et al. (2018): Evaluation of status of puberty in children and adolescents with end-stage renal disease undergoing maintenance hemodialysis. J Integr Nephrol Androl., 5:6-13.

15. Vivante A, Hildebrandt F et al. (2016): Exploring the genetic basis of early-onset chronic kidney disease. Nat Rev Nephrol., 12: $133-146$.

16. Fishbane S, Spinowitz B (2018): Update on Anemia in ESRD and Earlier Stages of CKD: Core Curriculum 2018. Am J Kidney Dis., 71(3):423-435.

17. Li N, Zhou H, Tang Q (2017): Red Blood Cell Distribution Width: A Novel Predictive Indicator for Cardiovascular and Cerebrovascular Diseases. Disease Markers, 708-9:493.

18. Bazeed M, Allam M, Bakeer M (2018): A Comparative Study of Platelet Parameters in Chronic Kidney Disease, End-Stage Renal Disease Patients Undergoing Hemodialysis and Healthy Individuals. The Egyptian Journal of Hospital Medicine, 71(6): 3429-3433.

19. Hartung E, Kim J, Laney $\mathbf{N}$ et al. (2016): Evaluation of Neurocognition in Youth with CKD Using a Novel Computerized Neurocognitive Battery. Clinical Journal of the American Society of Nephrology, 11(1): 39-46. 